\title{
Análise do alinhamento entre os atributos das transações e as formas de governanças empregadas na citricultura
}

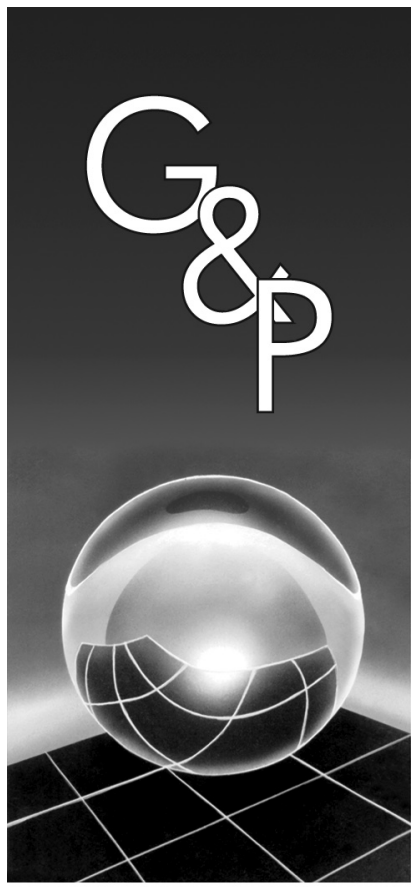

Fabiana Ortiz Tanoue de Mello

Luiz Fernando Paulillo

\section{Resumo}

Na Citricultura, o produtor coordena suas transações de venda de laranja para os agentes dos canais de distribuição, empregando diferentes estruturas de governança. Nas vendas para os barracões, intermediários, varejistas e mercado institucional, ele realiza transações baseadas no mercado spot. Já nas negociações com a indústria processadora de suco, predominam os arranjos contratuais. Há produtores, ainda, que assumem a função dos canais de distribuição, integrando a venda da fruta in natura para o consumidor final (hierarquia). O objetivo deste trabalho é analisar as transações realizadas pelos citricultores segundo os atributos propostos por Williamson (1985; 1991), no âmbito da Economia dos Custos de Transação (frequência, incerteza e especificidade de ativos), e verificar se as formas de coordenação empregadas para coordenar essas transações estão alinhadas a esses atributos. $O$ trabalho concluiu pela existência desse alinhamento e, consequentemente, que não há inabilidade por parte dos citricultores e membros dos canais de distribuição da laranja para mensurar as dimensões das transações e para identificar a solução mais eficiente em termos de governança, ou seja, aquela que minimiza os custos de transação.

Palavras-chave: Sistema agroindustrial citrícola. Estruturas de governança. Custo de transação.

\section{Introdução}

No âmbito do agronegócio, a questão da coordenação tem especial interesse, considerando-se a tendência, verificada nos últimos anos, de estreitamento das relações entre as diversas etapas produtivas. As crescentes exigências do consumidor de alimentos em relação a variedade, qualidade e segurança dos produtos, contrapostas à incerteza climática, com os aspectos intrínsecos de sazonalidade e perecibilidade da produção agrícola, aumentam o desafio dos atores em torno da coordenação de cada cadeia agroindustrial.

No âmbito das relações citrícolas, o processo de integração vertical da indústria em direção à produção agrícola e o fim do contrato-padrão aumentaram a complexidade das relações neste sistema agroindustrial, alterando as condições da negociação entre os agentes produtivos e impondo novas formas contratuais de compra e venda de laranja. Esses fatores aumentaram o poder de barganha da indústria nas transações com os citricultores, limitando o conjunto de formas de coordenação disponíveis para esse agente.

Neste contexto, torna-se relevante o entendimento das transações realizadas entre citricultores e os diversos canais de distribuição (indústria processadora, barracões, intermediários, varejistas e membros do mercado institucional) e o mapeamento dos mecanismos de governança empregados com o objetivo de reduzir os custos de transação e amenizar os riscos nas negociações. Assim, o objetivo principal do trabalho é verificar se as formas de coordenação empregadas pelos citricultores estão alinhadas aos atributos propostos por Williamson $(1985 ; 1991)$ no âmbito da Economia dos Custos de Transação, ou seja, a frequência e a incerteza das transações e a especificidade de ativos.

Após a introdução, no segundo item, faz-se uma revisão do referencial teórico que fundamenta o trabalho, apresentando os principais conceitos da Economia dos Custos de Transação, os pressupostos comportamentais que embasam essa teoria e as dimensões das transações que devem ser consideradas na escolha da estrutura de governança eficiente. O terceiro item traz uma explanação dos métodos e técnicas utilizados na pesquisa, bem como da forma de análise das informações colhidas na pesquisa de campo. No quarto item, são analisadas as transações entre 
citricultores e os compradores de laranja (indústria de suco e canais de venda da fruta in natura) na região selecionada, caracterizando-as segundo a frequência, a incerteza e a especificidade de ativos, e verificando o alinhamento desses atributos à forma de governança efetivamente empregada. Para confirmar tal alinhamento, também serão mensurados os custos incorridos nas transações realizadas pelos produtores. Nas considerações finais, expõem-se os resultados obtidos ao longo desta análise, de forma a embasar as conclusões.

\section{A Economia dos Custos de Transação - ECT}

\subsection{O arcabouço teórico da Economia dos Custos de Transação - ECT}

A transação como unidade de análise é um recurso científico relativamente recente na área da economia. $\mathrm{O}$ conceito de transação é definido por Williamson (1993) como a transformação de um bem ao longo de interfaces tecnologicamente separáveis. Já Zylbersztajn (1995) entende as transações como trocas de direitos de propriedade de bens ou serviços.

$\mathrm{Na}$ medida em que as transações podem assumir uma variedade de formas, faz-se necessário um arcabouço completamente sistematizado para que os propósitos dessas negociações sejam cumpridos. É nesse contexto que cresce a importância das governanças que permitem coordenar as transações econômicas, mostrando os limites dos modos de análise tradicionais e impulsionando os estudos da Economia dos Custos de Transação.

$\mathrm{O}$ arcabouço teórico da ECT aprofunda o conceito geral da firma, agora como um complexo de contratos regendo transações internas, tornando sua análise mais complexa, pois considera que os agentes econômicos se interagem visando reduzir não somente os custos ligados à produção - como pregava a economia ortodoxa -, mas também aqueles ligados às transações. Esse novo corpo de conhecimento, que teve suas primeiras contribuições na década de 30 , suplanta a preocupação até então dedicada à tecnologia e ao estado da produção, introduzindo custos comparativos de planejar, adaptar e monitorar tarefas sob diferentes formas organizacionais.

Uma das mais importantes contribuições à ECT foi a concepção inovadora de Coase (1937), que, procurando entender a origem e os limites da firma, ou seja, quais atividades deveriam ser produzidas pela própria firma e quais deveriam ser designadas a terceiros, passou a considerá-la como uma forma de coordenação das transações dos agentes econômicos alternativa ao mercado, o qual nem sempre funciona como um coordenador perfeito da produção. As ideias do Autor representaram um avanço para os estudos econômicos, já que até então a firma era conhecida como uma função produção, na qual os insumos eram transformados em produtos finais. Na visão neoclássica, a firma era uma entidade otimizadora, totalmente indiferente à sua estrutura interna e aos condicionantes do ambiente, exceto aos preços.

Para Coase (1937), o estabelecimento da firma, agora representada por um complexo de contratos regendo transações internas, se dá porque há custos para os atores usarem o mecanismo de preços para organizar a produção, sendo que este custo está relacionado a descobrir qual a relevância dos preços. Assim, a escolha do mecanismo de coordenação a ser utilizado depende dos custos incorridos, ou seja, dos custos de descobrir os preços vigentes no mercado (de coleta de informações), dos custos de negociação, do estabelecimento de um contrato e dos custos necessários para realizar inspeções necessárias para assegurar que os termos do contrato estão sendo observados. O Autor denominou estes custos de custos de transação e são eles que explicam, então, a existência das firmas.

A ideia genérica de Coase acerca das formas organizacionais e sua definição restrita de custos de transação foram aprofundadas e desenvolvidas por outros autores, que procuraram explicar como surgem os arranjos organizacionais e o processo de adaptação destes arranjos às mudanças no ambiente econômico, além de procurararem definir custos de transação de maneira mais completa, fornecendo os pilares da ECT.

Segundo Williamson (1985), os custos envolvidos em diferentes transações podem ser divididos em ex ante e ex post: ex ante se refere aos custos necessários à coleta de informações, à negociação, à redação do contrato e à elaboração de salvaguardas contratuais, de forma a minimizar eventuais lacunas que incitem a atitude oportunista das partes; ex post se refere às transações que dizem respeito aos possíveis custos de adaptações às cláusulas inicialmente acordadas e os custos de rompimento contratual, em função de falhas ou atitude oportunista de uma das partes. Existe uma interdependência entre estes custos, devendo ser considerados de forma simultânea e não sequencial.

North (1990) define os custos de transação como "os custos inerentes ao processo de troca, necessários para avaliar o desempenho, fiscalizar o cumprimento dos contratos e executá-los". Assim, quando advogados, banqueiros, contadores, gerentes e políticos entram na operação e na coordenação de qualquer sistema econômico, passam a existir custos de transação. Segundo o Autor, estes custos dependem dos atributos físicos dos bens e serviços transacionados (tamanho, cor, localização, qualidade), do desempenho dos agentes, dos direitos de propriedade incluídos na troca (direito de uso, de derivar renda e de excluir outros) e do tamanho do mercado (que determina se a troca é pessoal ou impessoal).

As críticas em relação aos custos de transação, que explicam por que a teoria de Coase demorou tanto tempo 
para ser aceita e aplicada (cerca de 30 anos), devem-se ao fato de esses custos não serem facilmente observáveis e mensuráveis, pois alguns elementos das transações são tácitos e seus custos não explícitos. Willianson (1985) argumenta que os custos de transação evoluem sempre em uma forma institucional, sendo importante compará-los entre diferentes estruturas de governança e não apenas mensurá-los.

\subsection{Pressupostos comportamentais}

O ponto de partida para a existência de custos de transação é o reconhecimento de que os agentes econômicos são racionais - porém, limitadamente - e oportunistas. Estes dois pressupostos comportamentais explicam por que é tão custoso transacionar.

Segundo Simon (1978), a racionalidade limitada dos indivíduos induz à incapacidade das partes em prever todas as contingências futuras relacionadas a uma transação, tornando os contratos incompletos. Mas, embora incompletos, os contratos serão possíveis, desde que os agentes não sejam dotados de oportunismo.

Em um contexto marcado pela limitação da cognição, uma das partes envolvidas na transação pode possuir alguma informação privada, não adquirível pela outra parte, sem custos. Neste caso, os agentes podem utilizar-se dessa informação em benefício próprio, abrindo espaço para o interesse próprio das partes que realizam uma transação (oportunismo), complicando os problemas de organização econômica.

Quando não há oportunismo, as transações não estão sujeitas a situações de incerteza, revelação incompleta e distorcida da informação, esforço premeditado para ocultar, ofuscar ou confundir a outra parte, e todo comportamento pode ser governado por regras.

Assim, de acordo com North (1990), a racionalidade limitada dos agentes torna os mercados incompletos e imperfeitos, acarretando custos de transação que decorrem dos altos custos de informação e do fato de as partes deterem informações de forma assimétrica. Por isso, mecanismos de coordenação específicos são necessários para que a transmissão da informação ocorra. A estrutura de governança eficiente para regular as transações é, então, aquela capaz de minimizar esses custos, promover maior coordenação e mais rápida adaptação às modificações no ambiente institucional, tecnológico e organizacional.

\subsection{Variáveis transacionais e as formas de governança}

Williamson (1991) distingue três formas básicas de governança das transações: a) mercado ou spot; b) formas híbridas ou contratuais; e c) hierarquia ou integração vertical. Para o Autor, há razões econômicas racionais para organizar algumas transações de uma maneira e outras transações de outra maneira, sendo que a governança adequada tem de ser capaz de resolver o conflito entre as partes e de impedir ou atenuar conflitos potenciais. Neste contexto, ele considera que estruturas eficientes de governança - ou seja, aquelas economizadoras de custos de transação - são resultados do alinhamento destas aos atributos das transações, sob condições de racionalidade limitada dos agentes e oportunismo. Os atributos fundamentais das transações são: a) especificidade dos ativos envolvidos; b) incerteza à qual as transações estão submetidas; e c) frequência com que se realizam as transações.

A especificidade dos ativos, que representa o mais importante indutor da forma de governança, corresponde a investimentos duráveis que se realizam em apoio a transações particulares, cujo custo de oportunidade é muito menor nos melhores usos alternativos se a transação original termina prematuramente (WILLIAMSON, 1985). Portanto, são ativos de propósitos especiais e não gerais, que não podem ser utilizados de forma alternativa sem uma perda considerável de valor. Williamson (1991) distingue cinco tipos de especificidade de ativos:

a) Especificidade locacional: refere-se à redução nos custos de transporte e armazenagem por meio da localização estratégica entre firmas de uma mesma cadeia produtiva;

b) Especificidade de ativos físicos: quando são requeridos instrumentos ou equipamentos especializados para a produção de um bem para o cliente;

c) Especificidade de ativos humanos: está relacionada às habilidades ou ao aprendizado específico de uma determinada atividade;

d) Especificidade de ativos dedicados: quando a expansão da capacidade produtiva é adotada por uma das partes com o propósito único de responder ao incremento da quantidade demandada pela outra parte, convertendo-se em ativo específico; e

e) Especificidade temporal: onde o valor de uma transação depende do tempo em que ela se processa. Inclui produtos nos quais o tempo é um fator fundamental para a atribuição de valor ou para a eficiência no processo produtivo.

Segundo Williamson (1991), o valor do investimento específico em outro uso será menor que no uso específico para o qual foi pretendido, tornando o ofertante "preso" à transação. O comprador, por outro lado, não pode recorrer a fontes alternativas de oferta e obter condições favoráveis em outra transação, já que os custos de oferta de capitais não especializados são maiores. Portanto, ele também está comprometido, aumentando a necessidade de respostas coordenadas das partes da transação e trazendo à tona a necessidade de compromissos com horizonte de tempo mais extenso - pelo menos o suficiente para recuperar os investimentos cujo uso alternativo pode ser limitado.

A incerteza ou risco, um segundo atributo das transações, tem importância central na ECT, em razão do pressuposto 
da racionalidade limitada dos agentes, segundo o qual os atores são incapazes de desenhar um contrato que contemple todas as contingências futuras.

A incerteza representa perturbações exógenas que afetam o processo de troca, sendo que as partes têm de se adaptar a elas. Para Hayek (1945) apud Williamson (1985), a incerteza pode ser de dois tipos: a primária, que depende do Estado e deriva de atitudes aleatórias e mudanças imprevisíveis, e a secundária, que deriva do fato daquele que toma decisões não poder conhecer os planos e intenções da outra parte (falta de comunicação).

No caso de transações que envolvem ativos específicos, o aumento da incerteza é mais importante. Isso ocorre porque as partes têm de elaborar um sistema para resolver os pontos da transação, pois as brechas contratuais serão, possivelmente, maiores.

A frequência com que a relação entre as partes é estabelecida é outra dimensão da transação. Este atributo é importante porque quanto mais transações houver, maior a possibilidade de diluir os custos de adoção de um mecanismo de governança complexo.

Williamson (1991) argumenta: quando as transações são esporádicas, com baixo nível de especificidade dos ativos, e quando os preços são suficientes para motivar os agentes, a forma pura de mercado pode representar a forma mais eficiente de coordenação, já que a hierarquia incorre em custos burocráticos desnecessários. Por outro lado, quando as transações são recorrentes, na presença de especificidade de ativos e de incerteza, a forma contratual é a mais indicada, pois reduz os riscos de oportunismo.

Portanto, a contribuição da ECT permitiu avançar na questão da eficiência organizacional, já que estruturas mal escolhidas ou mal adaptadas à transação levam a dificuldades de coordenação.

\section{Métodos, técnicas e forma de análise dos resultados}

Para analisar as transações realizadas pelos citricultores, segundo os atributos propostos por Williamson $(1985 ; 1991)$ no âmbito da Economia dos Custos de Transação, e verificar se as formas de coordenação empregadas estão alinhadas a esses atributos, foram aplicados questionários junto a uma amostra de 54 citricultores. Eles estavam localizados na maior região produtora de laranja do país, a região de Barretos (Barretos, Bebedouro, Monte Azul, Taquaral, Taiaçu e Pirangi), no estado de São Paulo. Nessa região, foram encontrados todos os aspectos do cinturão citrícola, quais sejam: pomares novos e velhos, várias processadoras e associações de citricultores, prestadores de serviços e produtores que vendem para todos os canais de distribuição.

Em um segundo momento da pesquisa, foram realizadas entrevistas semiestruturadas com alguns citricultores (Foram selecionados para entrevista 27 produtores de portes distintos e que comercializavam laranja com todos os tipos de compradores. Os resultados da análise quantitativa auxiliaram na identificação dos produtores a serem entrevistados), com os objetivos de entender aspectos contextuais das negociações de venda de laranja para os membros dos canais de distribuição e de ajudar a explicar os resultados da análise quantitativa. Portanto, as informações colhidas na pesquisa e, posteriormente analisadas, foram qualitativas e quantitativas.

Considerando-se a complexidade das transações entre citricultor e compradores de laranja, nas quais vários aspectos e variáveis estão envolvidos, a combinação de dois métodos de análise dos dados (quali-quanti) permite entender com maior grau de profundidade estes aspectos. Portanto, os dois métodos se complementam, permitindo responder as questões de pesquisa de forma mais apropriada, contribuindo para confirmar a teoria que embasa a análise. Neste contexto, o método quali-quanti é particularmente apropriado para pesquisas aplicadas, caso deste trabalho.

Na pesquisa de campo, foram coletadas informações que permitiram descrever as formas de governança empregadas nas negociações de venda de laranja e identificar quais são as especificidades envolvidas na produção da fruta, a frequência das transações e as percepções dos produtores quanto à incerteza e outros possíveis entraves à efetivação das transações. Para cada um desses atributos, foi construída uma proxy, que foi captada por meio das perguntas e respostas dos questionários aplicados nos produtores da região pesquisada. O Quadro 1 mostra a construção dessas proxies.

Para verificar a existência de alinhamento entre os atributos das transações citrícolas e as formas de governança empregadas, foram elaboradas estatísticas descritivas das variáveis analisadas (média, frequência, máximo, mínimo e desvio-padrão), com a realização de testes de hipóteses e regressões, tendo como variável dependente a 'porcentagem de caixas de laranja vendidas com contrato e via mercado pelo citricultor' e como variáveis explicativas, as proxies para os atributos de frequência, incerteza e especificidade de ativos (Quadro1).

O modelo usado para avaliar a consistência das estimações e comprovar a significância das variáveis foi o LOGIT, que é indicado para os casos em que a variável dependente é limitada, ou seja, o intervalo de valores é substancialmente restrito, como ocorre com a porcentagem de caixas de laranja vendidas com contrato e via mercado spot, que varia entre 0 e $100 \%$. O modelo LOGIT é de resposta binária, isto é, são regressões que utilizam funções de distribuição de probabilidade acumulada (f.d.a.), que produzem probabilidades de resposta entre zero e um (WOOLDRIDGE, 2006). Essa regressão utiliza a f.d.a. logística. A regressão logística é um modelo de regressão não linear em que a variável resposta (variável dependente) 
é a probabilidade de ter um resultado ou outro baseado em uma função não linear da melhor combinação linear das variáveis independentes. Segue a especificação geral desse modelo:

Seja $\hat{Y}_{i}$ o valor da variável dependente para o i-ésimo caso. Pode-se definir $\hat{Y}_{i}$ como (Equações 1 e 2):

$$
\hat{Y}_{i}=\frac{e^{\beta_{0}+\beta_{1} X_{1}+\beta_{2} X_{2}+\ldots+\beta_{k} X_{k}}}{1+e^{\beta_{0}+\beta_{1} X_{1}+\beta_{2} X_{2}+\ldots+\beta_{k} X_{k}}}
$$

e

$$
\ln \frac{\hat{Y}}{1-\hat{Y}}=\beta_{0}+\beta_{1} X_{1}+\beta_{2} X_{2}+\ldots+\beta_{k} X_{k}
$$

Os coeficientes do modelo Logit podem ser estimados pelo método da máxima verossimilhança e o objetivo é encontrar a melhor combinação de variáveis independentes que maximizam a verossimilhança. Os coeficientes dão os sinais dos efeitos parciais de cada $x_{j}$ sobre a probabilidade de resposta e a significância estatística de $\mathrm{x}_{\mathrm{j}}$ é determinada pela condição de poder se rejeitar $H_{0}: \beta_{j}=0$ a um nível de significância suficientemente pequeno.

A interpretação dos valores e sinais dos coeficientes dos modelos de regressão logística deve ser feita com muita cautela. Coeficientes de variáveis com sinais negativos indicam uma redução na probabilidade de sucesso do evento com a mudança de ocorrência da situação descrita pela variável.

Considerando-se que para a ECT a governança eficiente é aquela que está alinhada aos atributos da transação e que minimiza os custos envolvidos na negociação, estes custos foram mensurados e comparados para diferentes estruturas de governança, segundo a metodologia sugerida por Benhan e Benahn (1998). Nesse caso, a partir da identificação de várias transações a serem analisadas em detalhes, mensuraram-se os custos efetivos de negociação, de fazer cumprir os termos acordados e, também, o custo do tempo e do dinheiro empregado para que estas transações fossem efetivadas. Uma descrição mais detalhada de cada um desses custos é mostrada em sequência.

\section{Resultados e discussão}

Considerando-se que o objetivo do trabalho é verificar se existe alinhamento entre os atributos das transações e as formas de governança empregadas pelos citricultores nas transações com os canais de distribuição, o recorte mais ideal para a amostra de 54 produtores é aquele que os separa por estrutura de governança.

As formas de governança encontradas na região da pesquisa foram: mercado, contrato e hierarquia. O mercado representa a venda sem qualquer tipo de arranjo contratual, ou seja, as transações são feitas dia a dia na época da maturação da fruta e são motivadas pela busca do melhor preço por parte do comprador, que é definido pela oferta e demanda no momento da negociação. A identidade das partes não é relevante e as relações são esporádicas, não havendo compromisso de que a transação se repita no futuro. O contrato é empregado em transações que se desenvolvem em um período de tempo, em que as relações são continuadas e caracterizadas pela regularidade no volume transacionado, pela consistência na qualidade do produto e por certa padronização dos preços. Podem ser contratos com duração de uma safra, quando as negociações ocorrem baseadas na oferta e na demanda de laranja no ano de efetivação do contrato e os preços e a duração do contrato são baseados na demanda da própria processadora naquele período. Ou ainda contratos com duração de várias safras, quando o produtor comercializa um volume maior de laranja de qualidade superior com a indústria processadora, obtendo preços superiores ao de mercado. A hierarquia,

\begin{tabular}{|c|c|c|}
\hline Atributo & Proxy & Interpretações \\
\hline Frequência & Número de transações realizadas durante o ano/safra. & $\begin{array}{l}\text { Quanto maior o número de transações com um } \\
\text { comprador, maior a frequência. }\end{array}$ \\
\hline Incerteza & $\begin{array}{l}\text { Diferença entre o preço recebido pelo produtor pela caixa de la- } \\
\text { ranja }(40,8 \mathrm{~kg}) \text { e o preço esperado. }\end{array}$ & $\begin{array}{l}\text { A transação é marcada por incerteza quando } \\
\text { o preço recebido pelo produtor é diferente do } \\
\text { preço esperado (maior ou menor). }\end{array}$ \\
\hline $\begin{array}{l}\text { Especificidade } \\
\text { de ativos }\end{array}$ & $\begin{array}{l}\text { Física: se houver presença de investimentos em irrigação e/ou pro- } \\
\text { dução em grande escala da variedade de laranja Pêra Rio; } \\
\text { Humana: se houver presença de investimentos em assistência téc- } \\
\text { nica e em cursos de capacitação; } \\
\text { Locacional: quando o tempo de transporte da propriedade rural até } \\
\text { o ponto de entrega da laranja é menor que } 1 \text { hora ( } 60 \text { minutos); } \\
\text { Dedicada: se o produtor vendeu para o mesmo e único comprador } \\
\text { há pelo menos três safras consecutivas; e } \\
\text { Geral: se a laranja teve que ser vendida a um preço mais baixo, } \\
\text { caso não tenha sido destinada a um comprador específico. }\end{array}$ & $\begin{array}{l}\text { A transação envolve ativos específicos quando } \\
\text { pelo menos duas dentre as cinco especificidades } \\
\text { ao lado são detectadas. }\end{array}$ \\
\hline
\end{tabular}

Quadro 1. Construção das proxies para a análise dos atributos das transações citrícolas.

Fonte: a autora. 
quando o produtor é proprietário do barracão, de outros canais de distribuição da fruta in natura ou de alguma indústria processadora de suco.

Do total de 54 produtores pesquisados, totalizando 151 transações, 42 empregaram contrato para coordenar suas transações de venda de laranja na safra 2003/04, 11 usaram o mercado e 1 era integrado. A Tabela 1 sintetiza esses dados.

Em sequência, as transações analisadas serão caracterizadas segundo frequência, incerteza e especificidade de ativos, permitindo tirar conclusões acerca do alinhamento desses atributos à governança empregada para coordenar as transações de compra e venda de laranja.

\subsection{Frequência das transações}

A frequência com que a relação entre as partes é estabelecida é um atributo importante, porque quanto mais transações houver, maior a necessidade de salvaguardas contratuais para lidarem com imprevistos decorrentes de incompletude contratual (WILLIAMSON, 1985). Por outro lado, maior a possibilidade de diluir os custos de adoção de um mecanismo de governança complexo, como o contrato, por exemplo.

Nas vendas coordenadas por contrato, que são para a indústria processadora de suco, como cada lote vendido tem de ter uma escala mínima, o produtor pode realizar 1, 2, 3 negociações no ano ou até menos, quando o contrato tem a duração de 2 ou 3 safras. No caso das vendas governadas por mercado, que são para os agentes que destinam a fruta para o consumo in natura, as negociações também são pouco frequentes durante a safra.

A Tabela 2 mostra que o número de transações (frequência) é comparativamente maior na governança que promove um maior controle, a contratual, o que dá indícios de alinhamento entre esse atributo e a forma de coordenação empregada pelo citricultor.

\subsection{Incerteza}

A incerteza, segundo Williamson (1985), constitui-se em qualquer tipo de perturbação endógena que afeta o processo de troca, podendo ser primária (deriva de atitudes aleatórias e mudanças imprevisíveis) ou secundária (deriva do fato daquele que toma decisões não poder conhecer os planos e intenções da outra parte).

As principais incertezas relacionadas a produção e comercialização de laranja são: volume, qualidade e preços, sendo que somente o último tipo pode ser minimizado por meio da escolha de uma estrutura de governança eficiente. As variáveis que explicam a incerteza em relação ao volume são aleatórias, já que é praticamente impossível garantir que a doença ou a praga será controlada, mesmo seguindo as normas técnicas existentes. Qualquer variação de um componente não controlável no campo pode alterar o resultado da operação, como pode ocorrer com a mudança de clima.

Quanto à qualidade da laranja, a incerteza vem da especificidade temporal, já que a fruta pode perder a qualidade ao longo do tempo. Essa variável pode ser tratada pelo oportunismo quando estiver relacionada à assimetria de informação entre as partes, caracterizando uma incerteza secundária. Esse tipo de incerteza afeta mais a capacidade de negociar dos produtores que vendem para barracões, varejistas e outros mercados que destinam a fruta para mesa, já que a qualidade da laranja é o diferencial para obter preços melhores. No caso da indústria, embora essa incerteza também seja elevada, é mais comum a mensuração dos atributos responsáveis pela qualidade da laranja destinada à produção de suco por meio da análise física ou química da fruta.

Tabela 1. Número de produtores, número de transações e quantidade de laranja comercializada (caixas de 40,8 kg), sob diversas estruturas de governança - safra 2003/04.

\begin{tabular}{lcccrr}
\hline Governança & $\begin{array}{c}\text { Número de } \\
\text { produtores }\end{array}$ & $\begin{array}{c}\text { Número de } \\
\text { produtores (\%) }\end{array}$ & $\begin{array}{c}\text { Número de } \\
\text { transações }\end{array}$ & $\begin{array}{c}\text { Quantidade } \\
\text { comercializada }\end{array}$ & $\begin{array}{c}\text { Quantidade } \\
\text { comercializada (\%) }\end{array}$ \\
\hline Hierarquia* & 1 & 1,9 & 3 & 9.000 & 0,8 \\
Contrato & 42 & 77,8 & 122 & 1.087 .162 & 96,1 \\
Mercado & 11 & 20,3 & 26 & 34.426 & 3,1 \\
Total & 54 & 100 & 151 & 1.130 .588 & 100 \\
\hline
\end{tabular}

Fonte: Pesquisa de campo. * Como apenas um produtor é integrado (num total de 54), realizando somente 3 transações (dentre as 151 analisadas), essa estrutura de governança (hierarquia) não será considerada na análise dos dados.

Tabela 2. Frequência das transações citrícolas - safra 2003/04.

\begin{tabular}{ccccccc}
\hline Governança & Frequência & Média & Mínimo & Máximo & D.P & Valor P \\
\hline Contrato & 122 & 3,03 & 1 & 6 & 1,1637 & 0,0001 \\
Mercado & 26 & 2,15 & 1 & 4 & 1,0077 & 1,1715 \\
Total & 148 & 2,88 & 1 & 6 & 6 \\
\hline
\end{tabular}

Fonte: pesquisa de campo. 
Outra incerteza nas transações entre produtor de laranja e canais de comercialização vem da variação de preços da fruta comercializada. Essa incerteza pode ser considerada do tipo primária, se estiver relacionada às oscilações da oferta de laranja em função de fatores aleatórios (clima, pragas, etc.), ou do tipo secundária, se estiver associada à manipulação ou domínio de informações por uma parte da transação, podendo, nesse caso, ser minimizada por meio da escolha de uma estrutura de governança eficiente.

Considerando-se a variação entre o preço recebido e o preço esperado pelo citricultor como proxy para a mensuração da incerteza: há incerteza, quando o preço recebido for diferente do esperado; e não há incerteza, quando o preço recebido for igual ao esperado. A Tabela 3 não permite concluir pelo alinhamento desse atributo à forma de governança empregada, porque o teste de hipóteses indica que a variável é estatisticamente igual para as duas estruturas de governança. Ou seja, não é possível concluir que a incerteza de preços existe em maior proporção na governança que exerce maior controle sobre as condições da transação, a contratual, e em menor proporção nas negociações via mercado.

Contudo, nas entrevistas realizadas, os produtores relatam que há uma maior incerteza nos arranjos contratuais com a indústria, que pode ser explicada pelo fato de a safra ser negociada antecipadamente, quando a cotação do produto pode evoluir diferentemente do esperado. Assim, uma das partes fica mais propensa a romper o acordo, colocando a necessidade de contratos antecipados, com preços variáveis. Já nas vendas para os canais que destinam a fruta para mesa, a negociação do preço se dá no momento da venda, o que reduz a probabilidade de haver uma variação entre o valor recebido e o valor esperado pelo produtor.

Além disso, é importante considerar a assimetria de estrutura de mercado, de recursos e de informação que existe entre a indústria e os produtores de laranja, fato que acaba gerando maior incerteza nas negociações com esse canal de distribuição. Além do domínio da informação, outras estratégias são empregadas pela indústria para reduzir o preço de referência a ser pago pela caixa de laranja, aumentando a incerteza do citricultor nas negociações com esse canal:

a) a manutenção de pomares próprios, aumentando seu poder de barganha no início de cada safra; b) o compartilhamento e não divulgação de informações relativas a estoques estratégicos de suco de acordo com interesses de fechamento de preços de contratos futuros;

c) o acordo entre indústrias para não divulgação de seus custos de produção e distribuição de suco, bem como da produtividade média para transformação de caixas de laranja em toneladas de suco processado;

d) a administração de preços internos e externos por meio do controle da oferta no Brasil e na Flórida;

e) o pagamento de preços diferenciados a produtores, segundo critérios não definidos; e

f) a não divulgação com antecedência pelas indústrias da logística desejada para a colheita da fruta, o que dificulta a organização da atividade e a formação dos consórcios de produtores. (PAULILLO et al., 2006)

Assim, diferenças no poder de barganha exercem impactos importantes na escolha da governança, deixando disponível apenas um conjunto limitado de mecanismos. No caso analisado, há diferenças no poder de barganha entre o produtor e os membros dos canais de distribuição, que acabam definindo qual será o mecanismo que coordenará as transações.

\subsection{Especificidade de ativos}

A qualidade da laranja comercializada nos diversos canais de distribuição está ligada às características físicas, temporais e de localização dos pomares que, em muitas situações, podem tornar-se entraves para a produção e a negociação dos citricultores, influenciando na escolha da forma de coordenação.

Há um tempo prolongado para os pomares entrarem na fase produtiva e um período específico do ano no qual a maturação da laranja está no ponto ótimo para a colheita, sendo que o produtor não pode controlar totalmente o ciclo biológico do seu produto. A diversidade de variedades e a possibilidade de ocorrerem colheitas temporãs tornam difícil um planejamento preciso da colheita. Por outro lado, como se trata de um produto perecível, que perde qualidade com o tempo de espera para esmagamento, existe um elevado custo de se transferir a laranja de um período para outro, explicando a especificidade temporal desse produto.

A especificidade física pode advir dos seguintes aspectos: a) dos atributos exigidos pela indústria de suco, como teores de açúcar diferentes e ratio (relação entre o brix "\% de

Tabela 3. Diferença entre preço recebido e preço esperado (R \$/caixa de laranja).

\begin{tabular}{lcccccc}
\hline Governança & $\begin{array}{c}\text { Frequência (preço recebido } \\
\text { diferente do esperado) }\end{array}$ & $\%$ & $\begin{array}{c}\text { Frequência (preço recebido } \\
\text { igual ao esperado) }\end{array}$ & \% & $\begin{array}{c}\text { Frequência } \\
\text { total }\end{array}$ & $\begin{array}{c}\text { Valor P } \\
\text { Contrato }\end{array}$ \\
Mercado & 75 & 61,5 & 47 & 38,5 & 122 & 0,7431 \\
Total & 12 & 46,2 & 14 & 53,8 & 26 \\
\hline
\end{tabular}

Fonte: pesquisa de campo. 
sólidos solúveis no suco" e a acidez) considerado ideal, pois as características mais importantes que influenciam a qualidade do suco de laranja são os açúcares, ácidos, o gosto ou sabor, a concentração e a vitamina $C$, que são avaliados por diferentes métodos para definir e classificar esse suco; b) da variedade de laranja produzida, já que o citricultor que produz uma maior quantidade de laranja Pêra Rio tem maior facilidade de vender toda sua produção para a indústria, pois essa é a variedade preferida pelas processadoras, que chegam a pagar um preço melhor pela caixa dessa variedade; e c) a especificidade física mais relevante, dentre os produtores analisados, vem dos investimentos na produção agrícola, principalmente os destinados à irrigação. Esses investimentos estão presentes tanto na produção da fruta que será comercializada via mercado - quando o produtor zela pela elevada qualidade da fruta para mesa visando conseguir um preço maior - quanto na produção da laranja que será destinada à indústria de suco via contrato, já que o produtor consegue uma maior produtividade do pomar e, consequentemente, maior escala. Para avaliar a presença de especificidade física nas transações realizadas, foram consideradas como proxies a existência de investimentos em irrigação e o fato de a maior parte da produção de laranja ser da variedade Pêra Rio.

A produção de citrus também envolve especificidade humana, principalmente no tocante ao conhecimento e às habilidades especiais na produção e na colheita da fruta para o consumo in natura (sobretudo a laranja vendida para os barracões). Para avaliar a presença desse tipo de especificidade, a variável escolhida foi a existência de investimentos em assistência técnica e em cursos de capacitação por parte do citricultor.

Já a especificidade locacional se dá quando a maturação da fruta ocorre em locais distantes dos pontos de entrega, dificultando a logística e aumentando os custos de distribuição.

A especificidade dedicada é criada pela dependência que possui o produtor de laranja em relação a um comprador, ou seja, essa surge à medida que ele faz investimentos para ofertar laranja a um cliente específico. Esse tipo de especificidade é mais evidente entre os produtores que vendem laranja exclusivamente para um comprador do que entre os que vendem para diversos compradores, uma vez que, no primeiro caso, os citricultores comercializam com apenas uma empresa durante todo o ano/safra, constituindo-se em fornecedores cativos.

É fato que este conjunto de especificidades cria uma relação de dependência entre as partes da transação e torna os agentes presos a este tipo de negociação, pois, se a relação terminar, o valor do investimento realizado será menor em outro uso. Além disso, e o comprador fica comprometido, porque não pode recorrer a fontes alternativas de oferta e obter condições favoráveis em outra transação. Considerando-se esse fato, procurou-se capturar o efeito de todas as especificidades em conjunto por meio da verificação da perda de valor quando a laranja é destinada a um uso alternativo. Assim, foi questionado se o produtor consegue vender sua fruta, cuja produção exigiu investimentos específicos, a outros compradores sem perda de preço.

Para a construção da Tabela 4, que identifica a presença de ativos específicos nas transações realizadas pelos produtores, o seguinte critério foi empregado:

- Sim, a especificidade de ativos está presente: quando a transação é marcada por, pelo menos, dois tipos de especificidades dentre os cinco tipos analisados; e

- Não, a especificidade de ativos não está presente: quando a transação apresenta apenas um ou nenhum tipo de especificidade dentre os cinco tipos analisados.

A Tabela 4 mostra que a especificidade está mais presente nas negociações dos produtores que vendem para a indústria mediante arranjo contratual e no caso dos produtores que integram a comercialização da laranja por meio de barracões do que nas negociações via mercado, confirmando o alinhamento entre esse atributo e a forma de coordenação empregada. A grande maioria dos produtores que atuam em arranjos contratuais alegou ter uma redução de preço, caso necessitem vender sua produção para outros compradores, configurando a perda de valor gerada pela especificidade dos investimentos realizados.

Embora a análise realizada dê indícios de que as governanças empregadas pelos citricultores da região pesquisada estão alinhadas aos atributos das transações propostos por Williamson (1985), a elaboração de regressões usando como variáveis dependentes a "porcentagem de caixas de laranja vendidas pelo citricultor com contrato e via mercado spot" e como variáveis explicativas as proxies para os atributos de frequência, incerteza e especificidade de ativos, permite confirmar tal alinhamento.

A Tabela 5 apresenta os resultados das regressões elaboradoras no modelo LOGIT para as transações realizadas.

Pela Tabela 5, verifica-se que tanto a especificidade de ativos quanto a frequência das transações são variáveis significantes e têm o efeito esperado sobre as participações de contrato e de mercado na quantidade de laranja comercializada pelo produtor. Ou seja: a presença de especificidade de ativos e a maior frequência das transações aumentam a probabilidade de adoção da governança contratual e reduzem a participação da governança de mercado na quantidade de laranja comercializada, o que permite concluir pelo alinhamento entre esses atributos e as governanças empregadas.

Diversamente, a proxy relacionada à incerteza nas transações (diferença de preço) não é significante para explicar a participação de contrato e nem a de mercado, o que pode ser explicado pelo fato dessa variável não ter captado a incerteza que existe nas transações realizadas 
Tabela 4. Presença de especificidade dos ativos - safra 2003/04.

\begin{tabular}{ccccccc}
\hline Governança & Frequência $(\mathbf{s i m})$ & \% & Frequência (não) & \% & Frequência total & Valor P \\
\hline Contrato & 102 & 83,6 & 20 & 16,4 & 122 & 26 \\
Mercado & 8 & 30,7 & 18 & 69,3 & 26001 \\
Total & 110 & 74,3 & 38 & 25,2 & 148 & \\
\hline
\end{tabular}

Fonte: pesquisa de campo.

Tabela 5. Estimações.

\begin{tabular}{|c|c|c|c|c|}
\hline \multirow{3}{*}{$\begin{array}{l}\text { Nome da } \\
\text { variável }\end{array}$} & \multicolumn{2}{|c|}{$\begin{array}{c}\text { Participação } \\
\text { de contrato }\end{array}$} & \multicolumn{2}{|c|}{$\begin{array}{c}\text { Participação } \\
\text { de mercado }\end{array}$} \\
\hline & \multicolumn{2}{|c|}{ LOGIT } & \multicolumn{2}{|c|}{ LOGIT } \\
\hline & Coeficiente & Signif. & Coeficiente & Signif. \\
\hline Intercepto & $-1,158557$ & 0,053 & 1,060463 & 0,113 \\
\hline $\begin{array}{l}\text { Especificidade } \\
\text { de ativos }\end{array}$ & 1,587681 & 0,001 & $-1,994111$ & 0,000 \\
\hline $\begin{array}{l}\text { Frequência das } \\
\text { transações }\end{array}$ & 0,462247 & 0,096 & $-0,411304$ & 0,095 \\
\hline $\begin{array}{l}\text { Diferença de } \\
\text { preços (incerteza) }\end{array}$ & 0,548031 & 0,287 & $-0,573869$ & 0,323 \\
\hline
\end{tabular}

Fonte: a autora.

pelos produtores selecionados. Contudo, o sinal do seu coeficiente indica o efeito esperado sobre os mecanismos de governança adotados, ou seja, na presença de incerteza em relação ao preço recebido pelo produtor, maior a probabilidade de adoção de contrato e menor de mercado, o que permite concluir-se pelo alinhamento.

De acordo com Williamson (1985), quanto maior a especificidade de ativos, mais recorrentes as transações e maior a incerteza, maior a necessidade de controle sobre as condições da transação. Tal encadeamento exige respostas coordenadas das partes e compromissos mais longos para recuperar os investimentos, cujo uso alternativo pode ser limitado; explica-se, dessa forma, o emprego de contratos de médio e longo prazo nas vendas para a indústria. Por outro lado, o mercado é a escolha dos citricultores nos casos em que as negociações são menos frequentes, com baixa incerteza de preços e baixa ou nenhuma especificidade de ativos Em função de apenas três transações serem coordenadas de forma hierárquica, não foi possível estimar os modelos Logit e Probit para esses casos, pelo tamanho reduzido da amostra. Porém, analisando-se os dados de estatística descritiva para as transações, foi constatado que há ativos específicos, incerteza quanto à variação de preços e elevada frequência nas transações, permitindo concluir-se pelo alinhamento.

Ao ser verificado que as formas de governança empregadas pelos citricultores para coordenar as transações de venda de laranja estão alinhadas aos seus atributos, estas formas são, então, as ideais ou eficientes. Ou seja, são formas capazes de minimizar os custos de transação, segundo a ECT. Para analisar este aspecto, estes custos foram mensurados e comparados para diferentes estruturas de governança, segundo quatro tipos:

a) Custo de negociar: são os custos monetários que o citricultor tem para negociar os termos da transação, como preço, qualidade, quantidade, condições de transporte, termos de pagamento, etc. Neste item, entram gastos com transporte, ligações telefônicas, etc;

b) Custo monetário de fazer cumprir o contrato: gasto monetário que o citricultor teve para o comprador das laranjas cumprir o contrato (gastos com telefone, transporte, advogados etc.);

c) Custo de oportunidade do tempo: trata-se do custo despendido na negociação das transações (ex ante) e aquele necessário para fazer cumprir o contrato (ex post). Este custo corresponde a uma estimativa do valor monetário do tempo gasto pelo produtor rural para realizar ajustes dos termos de negociação e para forçar o cumprimento do acordo. Considera-se que os custos de negociação e monitoramento não podem ser resumidos a gastos efetivos em dinheiro; devem incluir, também, o tempo consumido para exercer essas funções. O custo de oportunidade do tempo foi então calculado proporcionalmente, de acordo com a média do valor de um dia de trabalho dos produtores de laranja na região analisada; e

d) Custo de oportunidade do dinheiro: é representado pelo atraso no pagamento do dinheiro recebido pelo produtor de laranja. Para tanto, foi feita uma estimativa do custo de oportunidade do dinheiro, tendo como base a taxa média de juros para o ano de 2003.

O primeiro tipo de custo é considerado um custo ex ante, ou seja, anterior à transação, se referindo aos custos necessários a coleta de informações, negociação, redação do contrato e elaboração de salvaguardas contratuais, visando minimizar eventuais lacunas que levem a atitude oportunista das partes. O segundo e o quarto tipo de custos são ex post às transações, ou seja, dizem respeito aos possíveis custos de adaptações às cláusulas inicialmente acordadas e aos custos de rompimento contratual, em função de falhas, erros e atitude oportunista de uma das partes. A Tabela 6 traz os valores dos custos de transação segundo cada estrutura de governança. 
Tabela 6. Custos de transação por governança (R \$ por caixa de laranja) - safra 2003/04.

\begin{tabular}{|c|c|c|c|c|c|c|}
\hline \multicolumn{2}{|c|}{ Governança } & \multirow{2}{*}{$\begin{array}{c}\begin{array}{c}\text { Custo de } \\
\text { negociação }\end{array} \\
122\end{array}$} & \multirow{2}{*}{$\begin{array}{c}\begin{array}{c}\text { Custo de fazer } \\
\text { cumprir o contrato }\end{array} \\
122\end{array}$} & \multirow{2}{*}{$\begin{array}{c}\begin{array}{c}\text { Custo de oportunidade do } \\
\text { tempo gasto para negociar } \\
\text { e fazer cumprir acordo }\end{array} \\
122\end{array}$} & \multirow{2}{*}{$\begin{array}{c}\begin{array}{c}\text { Custo de } \\
\text { oportunidade } \\
\text { do dinheiro }\end{array} \\
122\end{array}$} & \multirow{2}{*}{$\begin{array}{c}\begin{array}{c}\text { Custo } \\
\text { transação total }\end{array} \\
122\end{array}$} \\
\hline Contrato & Frequência & & & & & \\
\hline & Média & 0,0537 & 0,0018 & 0,0018 & 0,0004 & 0,0578 \\
\hline & DP & 0,0902 & 0,0083 & 0,0060 & 0,0020 & 0,0919 \\
\hline \multirow[t]{3}{*}{ Mercado } & Frequência & 26 & 26 & 26 & 26 & 26 \\
\hline & Média & 0,0000 & 0,0061 & 0,0082 & 0,0014 & 0,0157 \\
\hline & DP & 0,0000 & 0,0215 & 0,0159 & 0,0051 & 0,0369 \\
\hline \multicolumn{2}{|c|}{ Valor P } & 0,0000 & 0,3170 & 0,0450 & 0,3268 & 0,0002 \\
\hline
\end{tabular}

Fonte: pesquisa de campo.

O custo monetário que o citricultor tem para negociar os termos da transação (preço, qualidade, quantidade, condições de transporte e termos de pagamento) é o gasto mais relevante nas transações citrícolas, sendo o contrato a governança que apresenta valor mais elevado, confirmando o que diz a ECT.

Além de a elaboração de salvaguardas contratuais justificar os custos de negociação mais elevados, o problema de seleção adversa também contribui para explicar esse fato. Ou seja, em um ambiente caracterizado pela incerteza e assimetria informacional, no qual as agroindústrias detêm informações privadas importantes antes da negociação de compra e venda da laranja (como o volume dos estoques de suco, seu preço no mercado internacional e a quantidade de laranja produzida em pomares próprios), o contrato protege o produtor de ações oportunistas e garante o retorno relativo aos investimentos específicos realizados; porém, esse mesmo contrato que tem papel de proteger e garantir, aumenta os custos ex ante.

Diversamente, nas vendas para os agentes que destinam a fruta para o consumo in natura, como na maior parte dos casos, não há elaboração de contrato e o produtor tem baixos custos de negociação, ou seja, incorre em custos ex ante menores. Nas vendas para o mercado institucional e para muitos barracões, por exemplo, os custos de negociação foram nulos em 2003, uma consequência da continuidade da relação e da confiança estabelecida entre as partes durante os anos, justificando a inexistência de contratos formalizados nessas transações.

Nota-se que os gastos para fazer cumprir o contrato (ex post) são maiores na governança de mercado, o que era esperado em função da falta de controle que esse tipo de mecanismo promove sob as condições ex post às transações, em troca de incentivo (melhor preço). Esses custos elevados resultam da forma como os mecanismos de enforcement são realizados, ou seja, entrando várias vezes em contato para o comprador efetuar o pagamento ( $50 \%$ dos produtores que vendem no mercado spot precisam entrar pelo menos uma vez em contato com o comprador para que este efetue o pagamento). Nos arranjos contratuais, esse problema ocorre com menor frequência, em função do próprio controle que o contrato exerce por meio das cláusulas punitivas.

Tanto o custo de oportunidade do tempo para negociar e fazer cumprir o acordo quanto o custo de oportunidade do dinheiro são pequenos para os produtores que vendem sob todas as formas de governança, sendo pouco representativos se comparados ao preço da caixa de laranja recebido pelo citricultor, menos de 1\% (Embora os custos de transação pareçam pequenos, quando verificada sua participação no custo total do produtor, esses patamares assumem relevância, principalmente no caso das transações com a indústria processadora governadas por contratos " $7,4 \%$ dos custos totais").

Outro ponto importante verificado na pesquisa foi que o custo de transação ex ante é maior em três situações: 1) quando é negociada a espécie de laranja preferida pelo comprador (Pêra Rio); 2) quando o produtor está localizado mais distante do comprador; e 3) quando o produtor conhece o comprador há pouco tempo. Estes aspectos comprovam a argumentação de North (1990) de que os custos de transação dependem dos atributos físicos dos bens e serviços transacionados (tamanho, cor, localização, qualidade). Estes custos dependem, também, do desempenho dos agentes, dos direitos de propriedade incluídos na troca (direito de uso, de derivar renda e de excluir outros) e do tamanho do mercado (que determina se a troca é pessoal ou impessoal).

Portanto, a mensuração dos custos de transação para as diferentes estruturas de governança empregadas pelo citricultor também contribui para concluir-se pelo alinhamento aos seus atributos, sendo, então, a estrutura mais eficiente dentre todas as disponíveis para o produtor.

\section{Conclusões}

De modo geral, as especificidades de ativos envolvidas desde a plantação da laranja até a sua recepção nas processadoras de suco, a elevada incerteza e a forte assimetria de informações presentes nessas transações implicam na necessidade de 
contratos bem desenhados para a comercialização, para que problemas derivados do oportunismo e da racionalidade limitada dos agentes não ocorram. Na maioria das transações de venda para a indústria, a governança contratual é adotada, permitindo verificar o alinhamento entre os atributos das transações e a governança efetivamente empregada pela maioria dos produtores.

Já nas transações para os canais que destinam a fruta para o consumo in natura, a maioria das negociações não envolve investimentos específicos, sendo coordenadas sem a elaboração de contratos. Nesse caso, se o produtor não conseguir vender sua laranja para certo comprador, ele tem outras opções de compradores no mercado, sem incorrer em perda de valor. Em algumas negociações com barracões, em que há investimentos físicos, humanos e locacionais específicos, a ausência de contrato por ser explicada pela confiança estabelecida entre esse agente e o comprador ao longo de vários anos de relacionamento; essa confiança constitui-se como o fator que reduz a incerteza e leva a um enforcement automático das condições da transação, garantindo alguma coordenação em função do interesse das partes em manter o relacionamento.

Pela análise realizada, também é possível concluir que há necessidades específicas por parte dos compradores que pertencem a canais de distribuição distintos (quantidade, qualidade, localização etc.) e que essas necessidades geram restrições que também ajudam a explicar a escolha do produtor por determinada forma de governança.

Pela ótica da indústria, a necessidade de garantir regularidade no volume processado - minimizando a capacidade ociosa da planta e aproveitando as economias de escala - e a necessidade de obter consistência na qualidade da fruta processada tornam a governança contratual a mais eficiente para coordenar as transações de compra de laranja, reduzindo os riscos de ações oportunistas por parte dos fornecedores. Diferentemente, nas negociações com os agentes que destinam a fruta para o consumo in natura, a busca pelo melhor preço torna o mercado a governança mais indicada para o comprador.

Portanto, a verificação de que as formas de governança empregadas para coordenar as transações entre os citricultores e os diversos canais de distribuição estão alinhadas aos principais atributos propostos por Williamson (1985) indica que esses atributos são elementos-chave para se concluir um aspecto: não há inabilidade - por parte dos citricultores e membros dos canais de distribuição da laranja - para mensurar as dimensões das transações e para identificar a solução mais eficiente em termos de governança.

\title{
Analysis of the alignment between transaction attributes and forms of governance employed in citrus production
}

\begin{abstract}
In citrus production, the producer coordinates his sales transactions with agents of distribution channels employing different structures of governance. In sales to packing houses, middlemen, retailers and the institutional market, the producer utilizes transactions carried out in the spot market. In contrast, where the deals are with the juice-processing industry, contractual arrangements are predominant. There are also producers who act as distribution channels, integrating sales of the in natura fruit to the end consumer (hierarchy). This work aims to analyze the transactions performed by citrus producers, according to the attributes proposed by Williamson (1985 and 1991) in the field of Transaction Cost Economics (frequency, uncertainty and specificity of assets) in order to verify if the forms of coordination employed link up with the producer's deals aligned to those attributes. We conclude that such an alignment exists and there is no inability on the part of citrus producers or members of the orange distribution channels to measure the dimensions of their transactions as well as to identify the most efficient solution in terms of governance, i.e. that which minimizes transaction costs.
\end{abstract}

Keywords: Citrus agroindustrial system. Structures of governance. Transaction costs. 


\section{Referências bibliográficas}

AZEVEDO, P. F. A economia dos custos de transação. In: FARINA, E. M. et al. (Orgs.). Competitividade: Mercado, Estado e Organizações. São Paulo: Singular, 1997. 286 p.

BENHAM, A.; BENHAM, L. Measuring the Costs of Exchange. In: SECOND ANNUAL MEETING OF INTERNATIONAL SOCIETY FOR NEW ECONOMICS, Sep. 1998. Pantheon, Sorbonne, Paris: Université de Paris. Disponível em: <http://www.isnie.org/ISNIE98/ Benham-Benham.doc >. Acesso em: 26 Fevereiro 2007.

COASE, R. H. The nature of the firm. Economica, n. 4, p. $386-405,1937$.

GIL, A. C. Métodos e técnicas de pesquisa social. 2 ed. São Paulo: Atlas, 1987. $206 \mathrm{p}$.

NORTH, D. C. Institutions, institutional change and economic performance. Cambridge: Cambridge University Press, 1990. $152 \mathrm{p}$.

PAULILLO, L. F.(Org). Agricultura e citricultura no Brasil: diferenças e dominâncias. Rio de Janeiro: E-paper, 2006. 442 p.
SIMON, H. A. Rationality as process and as product of thought. The American Economic Review, v. 68, n. 2, p. 1-16, May 1978.

WILLIAMSON, O. E. Calculativeness, trust and economic organization. Journal of Law and Economics, v. 36, n. 1, part 2, p. 453-486, Apr. 1993.

Comparative economic organization: the analysis of discrete structural alternatives. Administrative Science Quartely, v. 36, n. 2, p. 269-296, Jun. 1991.

. The economic institutions of capitalism: firms, markets, relational contracting. New York: The Free Press, 1985. 450 p.

ZYLBERSZTAJN, D. Estruturas de governanca e coordenação no agrobusiness: uma aplicação da nova economia das instituições. São Paulo, 1995. Tese (Livre-Docência) - Faculdade de Economia, Administração e Contabilidade, Universidade de São Paulo.

WOOLDRIDGE, J. M. Introdução à Econometria: uma abordagem moderna. São Paulo: Thomson Pioneira, 2006. 684 p.

\section{Sobre os autores}

\section{Fabiana Ortiz Tanoue de Mello}

Economista pela Universidade de São Paulo - USP

Mestre em Engenharia de Produção pela Universidade Federal de São Carlos - UFSCar

Doutora em Engenharia de Produção pela Universidade Federal de São Carlos - UFSCar

Via Washington Luiz, Km 235, CEP 13565-905, São Carlos - SP, Brasil

e-mail: fabianaortiz@uol.com.br

\section{Luiz Fernando Paulillo}

Professor Assistente do Departamento de Engenharia de Produção da Universidade Federal de São Carlos - UFSCar

Doutor em Economia pelo Instituto de Economia da Universidade Estadual de Campinas - Unicamp

Pesquisador Científico do CNPQ - Bolsa Produtividade em Pesquisa (2007/2010)

Via Washington Luiz, Km 235, CEP13565-905, São Carlos - SP, Brasil

e-mails: dlfp@power.ufscar.br, dlfp@ufscar.br 